\title{
The Informational Basis of Social Judgments: Using Past Impression Rather Than the Trait Description in Forming a New Impression
}

\author{
YAACOV SCHUL \\ The Hebrew University of Jerusalem
}

AND

EUGENE BuRNSTEIN

The University of Michigan

Received December 10, 1983

\begin{abstract}
In making a new judgment, a person can access relevant past judgments and/ or process the stimulus information underlying these judgments. The present study is concerned with (i) the conditions under which past judgments are used instead of stimulus information and (ii) the effects that repeated past judgments have on the representation of the stimulus information in memory. Three experiments were conducted using an impression formation task. Subjects were presented with trait descriptions of hypothetical individuals and were asked to make one, three, or five impression judgments on the basis of each description. It was hypothesized that a new impression will tend to be based on an old one, rather than on trait information, as a function of the ease with which the new impression can be inferred from the old. Ease of inference, in turn, will depend on the similarity of the two impressions and the availability of the past impression. The results of the three studies are consistent with this hypothesis: When past judgments were available, (Expermints 1 and 3), the extent to which they, rather than the trait information, determined the present judgment increased with the similarity between them. However, when another activity interpolated between the old and the new judgments (Experiment 2), thus making the past judgment more difficult to access, the tendency to use the latter diminished considerably. After judging, subjects were given a surprise recognition test for the trait information. Recognition accuracy was superior following a series of related judgments than following unrelated judgments, suggesting that the elaborations and inferences
\end{abstract}

The research reported in this paper was supported in part by a grant from the National Science Foundation and a grant from the Hebrew University. Reprints can be obtained from Yaacov Schul, Department of Psychology, Hebrew University of Jerusalem, Jerusalem, Israel, or from Eugene Burnstein, Institute for Social Research, University of Michigan, Ann Arbor, MI 48106. 
activated by the stimulus information tend to accumulate more under related judgments than under unrelated ones. (๑) 1985 Academic Press. Inc.

While it may be impossible to step into the same impression twice, our present opinion of others is often highly influenced by the opinions we have formed about them in the past. The present study is concerned with the nature of this influence. More specifically, we examine the conditions under which new judgments are based on old ones rather than on the stimulus information (and vice versa). In addition, we attempt to demonstrate that the organization of the stimulus information in memory depends on how it is used in arriving at these judgments.

To begin with, let us describe the operations performed on the stimulus information when an impression is initially formed. We consider here three processes: comprehension, intregration, and abstraction (a more complete discussion can be found in Burnstein \& Schul, 1982; Schul, 1983). Comprehension refers to the interpretation of the stimulus information. It is highly dependent on the encoding schema so that the same stimulus may receive as many different interpretations as there are available encoding schemata (e.g., Alba \& Hasher, 1983; Higgins \& Rholes, 1976; Schneider \& Blankmaker, 1983; Taylor \& Crocker, 1981).

Once the stimulus information is understood, two additional operations must be performed, namely integration and abstraction. In impression formation, integration refers to the linking together of several traits into a unified description of a person (Burnstein \& Schul, 1982; Lingle \& Ostrom, 1979; Wyer \& Srull, 1981; Wyer, Srull, \& Gordon, 1984). The latter representation contains information directly given in the stimulus, as well as information adduced by elaborating upon the stimulus (Burnstein \& Schul, 1983, Carlston, 1980; see also Bransford, Barclay, \& Franks, 1972; Tsujimoto, 1978). Next, some global meaning, gist, theme, or summary is abstracted and stored separately in memory (N. Anderson \& Farkas, 1973; N. Anderson \& Hubert, 1963; Ebbesen, 1980; Posner \& Snyder, 1975; Schul, 1983; but see Wyer et al., 1984). This abstract code may be regarded the "pure" judgment inasmuch as it reflects the impression prior to it being translated into a particular response format. According to hierarchical network models of memory, such impressions are stored at the highest level of a tree structure, whereas the trait descriptions as well as the elaborations made on them are stored at lower levcls (e.g., Hastie \& Kumar, 1979; Schul \& Burnstein, 1983; Smith, Adams, \& Schorr, 1978).

If a series of judgments is made about the same person, then the later judgments can be characterized by the type of information upon which they are based, that is, whether they use the abstract code of an earlier impression or the stimulus information that underlies it. Recent research has documented that when individuals are asked to make two judgments 
about another, the second of which is memory based, this later judgment tends to depend mostly on the earlier one and little on the trait information (Carlston, 1980; Lingle \& Ostrom, 1979; Lingle, Geva, Ostrom, Leippe, \& Baumgardner, 1979; Loken, 1984; Sherman, Zehner, Johnson, \& Hirt, 1983; Wyer et al., 1984; but see Lingle \& Ostrom, 1979, and Lingle, Dukerich, \& Ostrom, 1983, for conditions under which individuals do use the trait information in memory-based judgments). The present study attempts to extend these findings by exploring the conditions under which a new impression will be derived from an old one, rather than from the stimulus information when the stimulus information is actually present.

Let us consider the case in which individuals are asked to make the second of two identical judgments. Even if the stimulus information were present, it would not be surprising if they paid no attention to it and simply retrieved the earlier judgment, reporting it as the new judgment (see "selection" rule (Step 3) in Smith, 1984). This is unlikely to occur, however, when individuals are instructed to make a series of completely unrelated judgments. To wit, if two judgements are completely unrelated, by definition, one judgment cannot be inferred from the other. Under these conditions, therefore, individuals are likely to ignore the old judgment and to reprocess the stimulus information in the making of the new judgment. Note that processing in this circumstances is likely to require reencoding of the information within a new interpretive schema (see below). Finally, there is the inbetween case in which the second judgment is neither irrelevant nor identical to the first, but is related to it. Here, the person may make use of the earlier judgment, the stimulus information, or, most likely, both.

To summarize, even though in all three cases-identical, unrelated, and related-a later judgment can be made on the basis of the stimulus information alone, this, in fact, is unlikely to happen. According to our analysis, after individuals have made several identical judgments they will be most likely to access their earlier judgments and least likely to process the stimulus information. After individuals have made several related judgments, they are likely to access the earlier judgment as well as to process the stimulus information. And finally, after individuals have made a series of unrelated judgments they are least likely to access their earlier judgments and most likely to process the stimulus information.

If this analysis is correct, two types of predictions can be made. First, it is likely that judgments based on the abstract code, here, the past impression, are faster than ones that are based on the underlying stimulus information, here, the trait description, since the later judgments are based on several traits that may require integration. Therefore, the time needed to make the second of two judgments should depend on the relationship between them: Later identical judgments will be fastest, while later unrelated judgments will be slowest. This follows because if 
earlier and later judgments are identical, individuals need activate only a single piece of knowledge, namely, the abstract code, and can ignore the stimulus information. If the two judgments are unrelated, individuals can ignore the abstract code, but they must reencode several pieces of knowledge, namely, the stimulus information.

The case for related judgments is less straightforward. Under related judgments individuals may not be able to use only the abstract code, as is hypothesized to be the case in identical judgments. Therefore, they should be slower than those under identical judgments. On the other hand, because the judgments are related, individuals can use the same interpretive schemata, which may not be less time-consuming than the reencoding of the stimulus information required in the case of unrelated judgments.

The second implication of our analysis follows from the assumption that the encoding of the stimulus information over a series of judgments depends on the relationships among these judgments. Specifically, when the stimulus information is not activated during later judgments, which is hypothesized to be the case when the judgments are identical, it can receive no additional elaboration. On the other hand, when the stimulus information is activated, which is hypothesized to be the case if the judgments are either related or unrelated, it is quite likely to receive additional elaboration.

There is, however, an important difference in the nature of elaboration under the conditions of related and unrelated judgments. When two judgments are related, then the schema used in processing the information during the first judgment will be similar to the one used in processing the information in the second judgment (or possibly even the very same schema). Hence, the elaborations and inferences made during successive judgments can accumulate. That is, each new judgment adds to the underlying representation so that at the end of the series it will constitute a relatively rich and strongly connected structure.

If, on the other hand, the two judgments are unrelated, the stimulus information is likely to be processed within a different interpretive schema each time. Under these circumstances, the elaborations activated during an first judgment may be irrelevant to or inconsistent with those formed during the second. Thus, elaborations and inferences will not accumulate from one judgment to another, as is the case in related judgments, but rather, those made during the earlier judgment must be replaced during the second judgment. In short, after a series of unrelated judgments, therefore, the stimulus information will be less strongly interconnected than after a series of related judgments. The upshot of this analysis is that memory for a trait description that has undergone several related judgments ought to be superior to the memory for a trait description 
that has undergone either several unrelated or several indentical judgments (J. Anderson, 1976; Craik \& Tulving, 1975; Reder, 1979).

\section{EXPERIMENT 1}

Impressions are expected to be formed most rapidly when the old and new judgments are identical, less rapidly when they are related, and most slowly when they are unrelated. As to memory for the stimulus information, namely, the trait description giving rise to the impression, it ought to be most easily retrieved following related judgments and least easily retrieved following identical judgments. To test these hypotheses, subjects were presented with descriptions of hypothetical individuals and were asked to make one, three, or five judgments on the basis of each description. Judgments varied in their degree of relateness, so that they were either identical, related, or unrelated. Following the judgments, subjects were given a surprise recognition test for the traits in the original descriptions.

\section{Method}

\section{Subjects}

Eighteen undergraduate students at the University of Michigan participated in the experiment as a part of their introductory psychology class requirement.

\section{Apparatus}

Subjects were seated in individual booths, equipped with a 12-in. CRT monitor, a sixbutton response panel (buttons labeled from " 1 " to " 6 "), and two single-buttons boxes (labeled $O L D$ and NEW). Presentation of the stimuli was controlled by a PDP-11/20 computer, with subjects' responses and latencies recorded under a program control.

\section{Design}

Each description (three traits) was judged one, three, or five times. These judgments were either similar to each other (related judgments hereafter), unrelated, or identical (i.e., the same judgment was repeated). Every subject rated two trait descriptions in each combination of the above factors (repetitions and judgment type).

\section{Stimuli}

Descriptions. Eighteen descriptions were constructed from traits drawn from N. Anderson (1968). Each description contained a common name and three traits (e.g., "Mike is naive, prideful, and shy"). The traits were assigned to descriptions randomly with the following restrictions: (a) likability value between 225 and 375 ; (b) the three traits in a description were not antonyms or synonyms; and (c) the traits were not synonyms or antonyms of the judgment dimensions.

Judgments. The dimensions for the related judgments were taken from the same cluster of personality characteristics in Rosenberg (1977, p. 228). The dimensions for the unrelated and identical judgments were drawn at random from N. Anderson's (1968) list of adjectives (see Footnote 1). Three different sets of dimensions were used in the experiment. Each set contained 5 related dimensions, 5 unrelated dimensions, and an 11th dimension to be 
used in the identical judgments. ${ }^{1}$ Subjects were presented with all 11 dimensions from one set ( 5 related, 5 unrelated and 1 identical), 7 dimensions from a second set ( 3 related, 3 unrelated, and 1 identical), and 3 dimensions from the third set (the single judgments). Sets were rotated between subjects, and dimensions were selected randomly within dimension type. Trait descriptions and judgment dimensions were paired randomly and differently for each subject.

\section{Procedure}

Judgmental phase. In each trial the name of the person associated with the description was presented on the CRT screen. One second later, the description (three traits) and the dimension of judgment were displayed. The dimension of judgment appeared embedded within a 6-point response scale. For example, subjects were asked to rate how HONEST Mike is, given that he "naive, prideful, shy." Their response was given on a 6-point scale, with " 1 " marked with not at all HONEST, and " 6 " marked with extremely HONEST. Subjects indicated their response by pressing one of six buttons that corresponded to the above scale. Once the response was made, the screen was erased and a new trial began.

Subjects were not told whether they would rate the stimulus information once, three times, or five times. Rather, they were warned that they may have to form impressions more than once on the same stimulus person. They were instructed to consider all the information associated with the stimulus person every time before they responded. To maximize the availability of the past judgments, subjects received each description, and made all judgments of that particular description, on successive trials. There were 54 trials in this phase.

Recognition phase. During each trial subjects were presented with a name of a person accompanied by two traits. One of these traits was always a member of the description of that person. In half of the trials, the second trait in the recognition probe was a completely new trait (a "new" probe"). In the remaining trials both traits in the probe had appeared together in the description (an "old" probe). Subjects were asked to determine whether the probe in each trial was old or new. They responded by pressing a button with the label $O L D$ to indicate an old probe, and another button labeled $N E W$ otherwise. There were 108 trials in this part ( 3 old and 3 new for each one of the 18 descriptions). The 3 old probes consist of the three possible pairs of traits, the 3 new probes consist of pairs of an old trait and a new one.

As practice, prior to each phase of the experiment, subjects rated descriptions different from those that appear in the study proper. The order of presentation of the descriptions and judgment dimensions as well as the pairing of descriptions to dimensions of judgments were randomized differently for each subject.

\section{Results and Discussion}

\section{Judgmental Phase}

Subjects formed an impression of a person based on a trait description one, three, or five times. These judgments were either identical, related, or unrelated to each other. Judgment latencies (i.e., the time interval

${ }^{1}$ The following three sets of dimensions were used in the experiment. The first 5 dimensions in each set were used for the related judgments, the second 5 were used for the unrelated judgments, and the 11th was used for the identical judgments: Set 1: happy, humorous, popular, warm, sociable, kindly, opportunist, reasonable, spendthrift, productive, casual; Set 2: helpful, modest, sentimental, sincere, tolerant, well spoken, forgiving, patient, apprehensive, resigned, responsible; Set 3: artistic, daring, persistent, skillful, intelligent, capable, cold, foolish, deceptive, generous, guarded. 


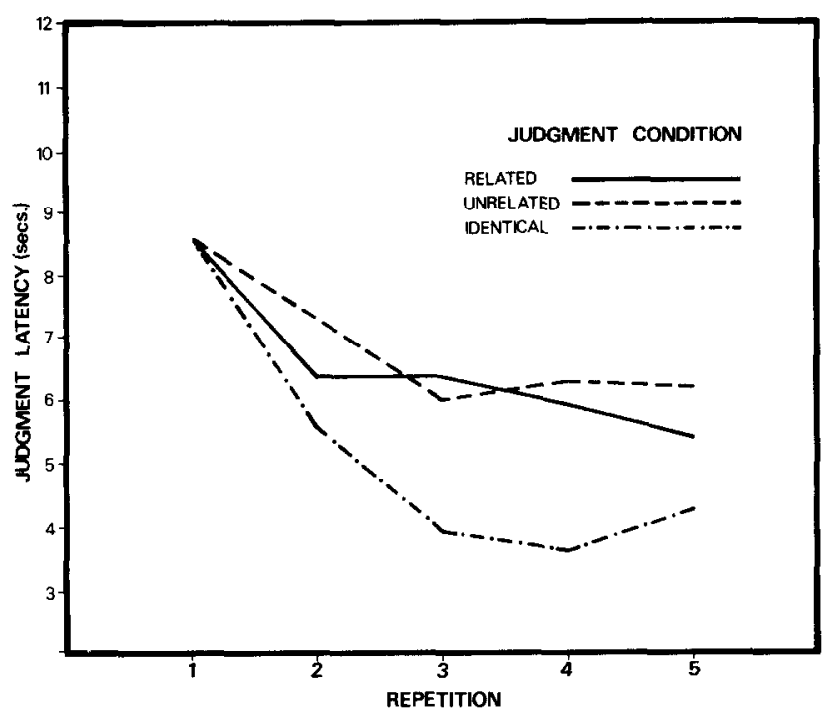

Fig. 1. Judgment latency as a function of judgment repetition and judgment relatedness (Experiment 1).

from the appearance of the description on the CRT to the subject's response) were averaged for each subject, separately in each level of judgment type $\times$ judgment repetition (i.e., the first time the description was rated, the second time, . . . , the fifth time). The means are presented in Fig. 1.

Two analyses were performed on these latencies. First, in order to assess the main effect of judgment repetition (averaged over judgment types), the entire data set was analyzed in a two-way repeated measures ANOVA [judgment type (identical, related, unrelated) $\times$ judgment repetition $(1,2,3,4,5)]$. The main effect due to judgment type as well as the interaction, however, could not be evaluated from this analysis because the first judgment, by definition, is neither identical, related, or unrelated. Therefore, the main effect of judgment type as well as the interaction were assessed from an ANOVA using a reduced data set, that is, excluding the results from the first judgments. The same procedure was applied in all analyses reported herein.

It was hypothesized that the tendency to base the current judgment on the previous ones will depend on the similarity between the judgments. There was, in fact, a significant judgment-type effect, $F(2,34)=11.50$, $p<.01$, indicating that unrelated judgments $(M=6.41 \mathrm{~s})$ took longer to make, albeit not significantly so, than related judgments $(6.02)$, which in turn took significantly longer than identical judgments $(4.35, t=3.21){ }^{2}$

${ }^{2}$ A $95 \%$ confidence level is used in the pairwise comparisons. 
The speed of judgment was also determined by the judgment repetition, $F(4,68)=23.87, p<.01$. As expected, later judgments were faster than earlier ones. Trend analysis with orthogonal trend components revealed a linear, $F(1,17)=39.50$, as well as a quadratic, $F(1,17)=18.90$, effects. Inspection of Fig. 1 suggests that the largest drop in latencies occurs between the first $(M=8.57 \mathrm{~s})$ and the second $(M=6.39)$ judgments. The decrease in judgment latencies between the second and the third $(M=5.42)$ was also statistically significant. There seemed to be no improvement in judgment speed beyond the third repetition.

The interaction between judgment type and judgment repetition failed to reach significance, $F(6,102)=1.60, p=.15$, indicating that the pattern of superiority of identical judgments to related judgments and of related judgments to unrelated judgments tends not to vary across repetitions.

\section{Recognition Phase}

During this part of the experiment subjects were presented with six recognition probes for each original description (from the judgmental phase). For each subject we computed the proportion of correct responses for each combination of judgment type (identical, related, or unrelated) and the number of judgments made in the first part $(1,3$, or 5). Means are presented in Fig. 2.

There was a statistically significant number of judgments effect, $F(2,34)=9.49, p<.01$. Accuracy following one judgment $(0.66)$ was

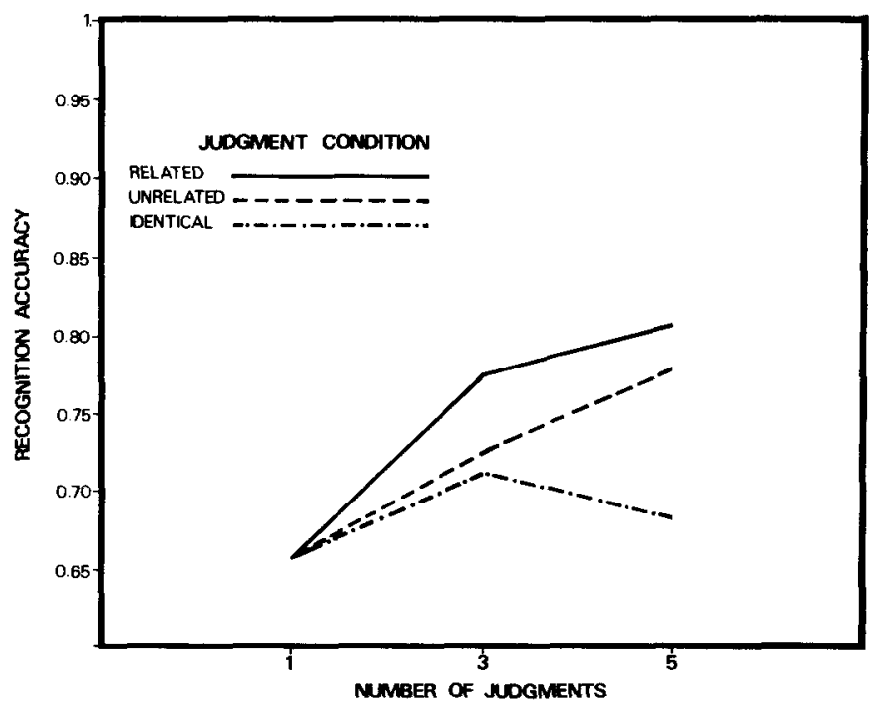

F1G. 2. Recognition accuracy as a function of the number of judgments and their relatedness (Experiment 1). 
inferior to that following three judgments $(0.74)$. The latter, however, was not significantly different from accuracy following five judgments (0.76).

Even though unrelated judgments took longer to make than related judgments, recognition accuracy under conditions of unrelated judgments was hypothesized to be inferior to that under related judgments. This follows from our assumption that the associative structure built during a new judgment cannot be easily assimilated to the one built during the old judgments when the judgments are unrelated, whereas it can when they are related. In fact, there was a statistically significant judgmenttype effect, $F(2,34)=6.79, p<.01$. Recognition memory following related judgments $(0.80)$ was superior to that following unrelated judgments $(0.76, t=2.10)$, and the latter was superior to the recognition memory following identical judgments $(0.70, t=3.15)$. The two-way interaction failed to reach significance, $F(2,34)=1.17, p=.32$, indicating that the superiority in recognition of related judgments over unrelated or identical judgments was not affected strongly by the repetitions (i.e., three or five).

These results suggest that when the representation of the past judgment, that is, the abstract code, is available, people will use it as a function of the similarity between the judgments. This occurs even when the trait information is highly available. Suppose, however, the abstract code was not readily available. Then the trait description should be used regardless of the similarity between the judgments (cf. Jacoby, 1978). In this case, therefore, unlike that in Experiment 1 (a) the speed of judgments in a series should not vary with the relatedness of the judgments and (b) the memory strength of the stimulus information should vary as a function of the number of judgments (Hintzman, 1974, 1976; Johnston \& Uhl, 1976; Shaughnessy, 1976) but not as a function of the similarity between the judgments. Experiment 2 tests these hypotheses.

\section{EXPERIMENT 2}

\section{Method}

Subjects

Eighteen undergraduate students at the University of Michigan participated in the experiment as a part of their introductory psychology class requirement.

\section{Stimuli, Design, and Procedure}

The trait descriptions, the dimensions of judgment, and the experimental design were identical to those in Experiment 1. The only difference between Experiment 1 and the present experiment lies in the order in which judgments were made. Recall that in Experiment 1 each description and all judgments associated with it were presented in successive trials. In order to reduce the availability of past judgments, subjects in the present experiment received the descriptions and made the judgments in a random order, so that judgments of any one description were intermixed with judgments of other descriptions, with the constraint that they could not be made in succession. 


\section{Results and Discussion}

\section{Judgmental Phase}

Judgment latencies were averaged for each subject in each level of judgment type $\times$ repetition. Figure 3 presents the means of these scores.

There were marginally significant differences due to type of judgment, $F(2,34)=3.08, p=.06$. Even though this effect is much weaker than the corresponding effect in Experiment 1, it was similar in direction, namely unrelated judgments were most difficult to make $(M=9.1 \mathrm{~s})$, whereas identical judgments were easiest to make $(M=8.0)$. There were no overall significant differences between the five repetitions, $F(4,68)$ $=1.51, p=.20$, with none of the trend components being significant $(F$ 's $<1)$. The interaction also failed to reach significance, $F(8,136)=$ 0.42 . It seems, therefore, that the manipulation succeeded in reducing the use of old judgments in making the new ones.

\section{Recognition Phase}

For each subject the proportion of correct responses was computed for each level of judgment type and number of judgments. They are displayed in Fig. 4.

The judgment latency results (above) indicate that there was little difference in the degree of use of the stimulus information as a function of judgment type. Correspondingly, accuracy performance should not be highly influenced by this factor. There were, in fact, no statistically

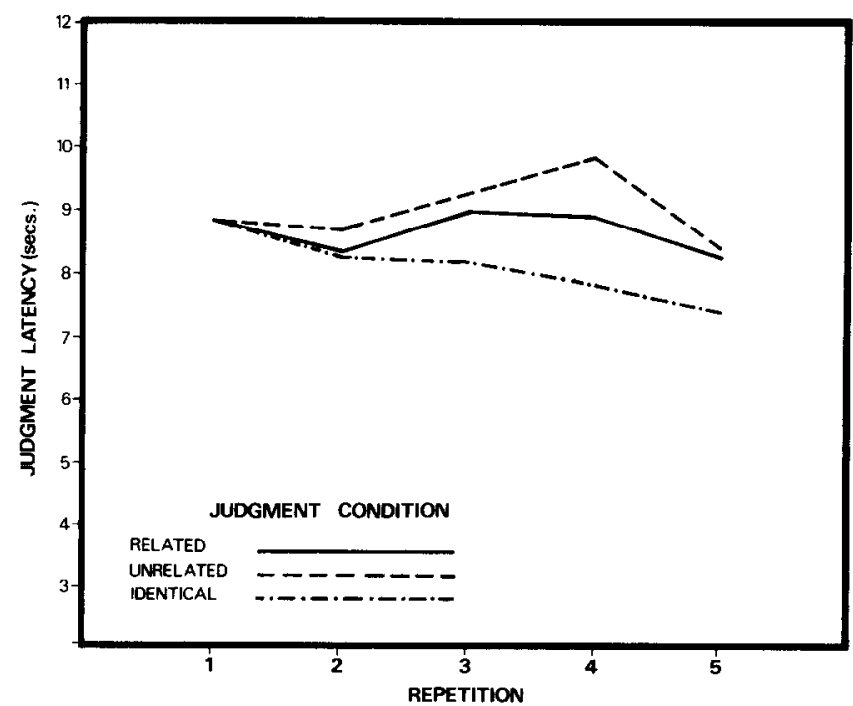

FiG. 3. Judgment latency as a function of judgment repetition and judgment relatedness (Experiment 2). 


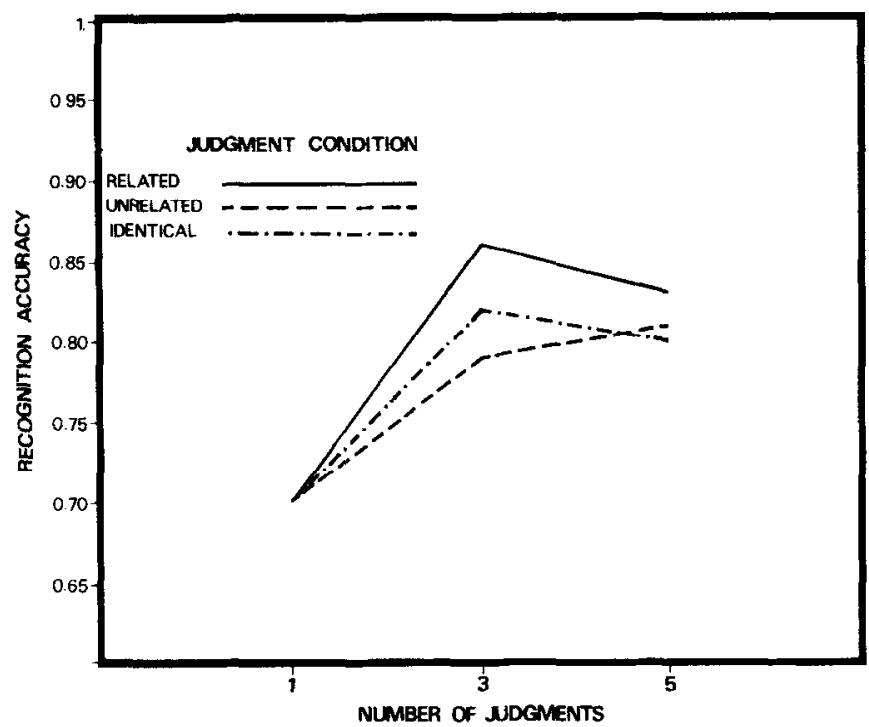

FIG. 4. Recognition accuracy as a function of the number of judgments and their relatedness (Experiment 2).

significant differences between the three types of judgments, $F(2,34)=$ $1.59, p=.2$. Furthermore, since the stimulus information is activated in memory every time a judgment is made, regardless of whether the judgments is identical, related, or unrelated, its representation ought to be strengthened with additional judgments. Indeed, the number of judgments effect was statistically significant, $F(2,34)=15.22, p<.01$, and this effect did not vary as a function of the type of judgments, as indicated by the nonsignificant interaction, $F(2,34)=0.35$.

The results of the two experiments provide support for the proposed model: When past judgments were highly available (i.e., Experiment 1). the extent to which they (rather than the stimulus information) determined the present judgment increased with the similarity between the judgments. However, when the past judgments were not highly available (i.e., Experiment 2), the differences between the three types of judgments diminished considerably. A third experiment was carried out to provide still further evidence along these lines.

\section{EXPERIMENT 3}

This experiment attempted to replicate the finding of Experiment 1 using a different recognition measure. During the recognition phase in our first two experiments, subjects were presented with either an "old" probe (i.e., a name and two traits that were both in the original description), or a "new" probe (i.e., a name and two traits, one of which was not part of any original description). We assumed that the associative links 
between the two traits in an "old" probe were stronger than those between the two traits in the "new" probe and that the difference in strength was an increasing function of the kind of encoding (i.e., whether elaborations do or do not accumulate) as well as the repetitions.

Experiment 3 used a stronger version of the recognition test. During each trial subjects were presented with four traits. Three of the traits belonged to the same original description. The fourth was a member of a different description. Note, however, that all four traits appeared equally often during the judgment phase. Subjects were to indicate the three traits that belonged to the same description.

This recognition test has two advantages over the "old/new" technique used in the previous experiments. First, it is a forced-choice procedure and hence it reduces possibilities of response biases. Second, the recognition reponse cannot be made on the basis of the familiarity of the information but rather must be made on the basis of its organization (Mandler, 1980). In other words, because all four traits appeared during the judgment phase, this response can be done only on the basis of the intradescription associations.

\section{Method}

\section{Subjects}

Twenty-four students at the Hebrew University participated in the experiment. All were native English speakers. They were paid for their participation.

\section{Stimuli and Design}

The trait descriptions, the dimensions of judgment, and the experimental design were identical to those in Experiment 1. During the judgment phase, each subject rated two descriptions in each combination of judgment type (identical, related, and unrelated) and number of judgments (one, three, and five). In the recognition phase, subjects were tested twice with each of the 18 original descriptions.

\section{Procedure}

The judgmental phase was identical to that in Experiment 1. During each trial in the recognition phase, a name and two cue traits appeared on the screen. Shortly after, two additional traits (the choice traits, hereafter) were also displayed. One of the choice traits, the correct alternative, had been presented together with the two cue traits and the name during the judgment phase. The other choice trait, the foil, belonged to a different description. Subjects were to indicate which of the two choice traits was the correct alternative. They responded by pressing one of six buttons that corresponded to the following scale: If the left-side choice trait was the correct alternative, they were to press one of the buttons labeled " 1 ", " 2 ", or " 3 " ("1" indicated most confident, "3" indicated least confident). If the right-side choice trait was the correct alternative, they were to press one of the numbers " 4 ", " 5 ", or " 6 " (" 4 " indicated least confident, " 6 " indicated most confident). The position of the correct alternative was determined randomly in each trial.

Descriptions containing foils and correct alternatives were selected randomly for each subject with the constraint that the description containing the foil was rated during the judgment phase the same number of times as the description containing the correct alternative. 


\section{Results and Discussion}

\section{Judgment Phase}

The mean judgment latencies in the different conditions appear in Fig. 5. There were significant differences between the five repetitions, $F(4,92)=74.20, p<.01$. Trend analysis revealed significant linear, $F(1,23)=111.26$, quadratic, $F(1,23)=68.63$, and cubic $F(1,23)=$ 33.41 components. The pattern of means paralleled that in Experiment 1. The largest drop in judgment latencies occurred between the first (11.23 s) and the second (6.24) judgments. The difference between the second and third judgments (5.46 s) was also significant. The third, fourth (5.47 $\mathrm{s})$, and fifth (5.74 s) judgments were not different from each other.

There were significant differences due to the type of judgment, $F(2,46)=52.24, p<.01$. In accordance with Lingle and Ostrom (1979), unrelated judgments took longer to make $(7.32 \mathrm{~s})$ than related judgments (6.30, $t=2.37)$, which, in turn, took longer to make than identical judgments (3.56, $t=6.37$ ). As in Experiment 1, the interaction was not significant, $F(6,138)=1.75, p=.11$.

\section{Recognition Phase}

During each recognition trial, subjects were given two cue traits and two choice traits. They were to indicate which of the choice traits belonged to the same description as the cue traits. Responses were given on a 6point scale that reflected both the accuracy of response and the confidence

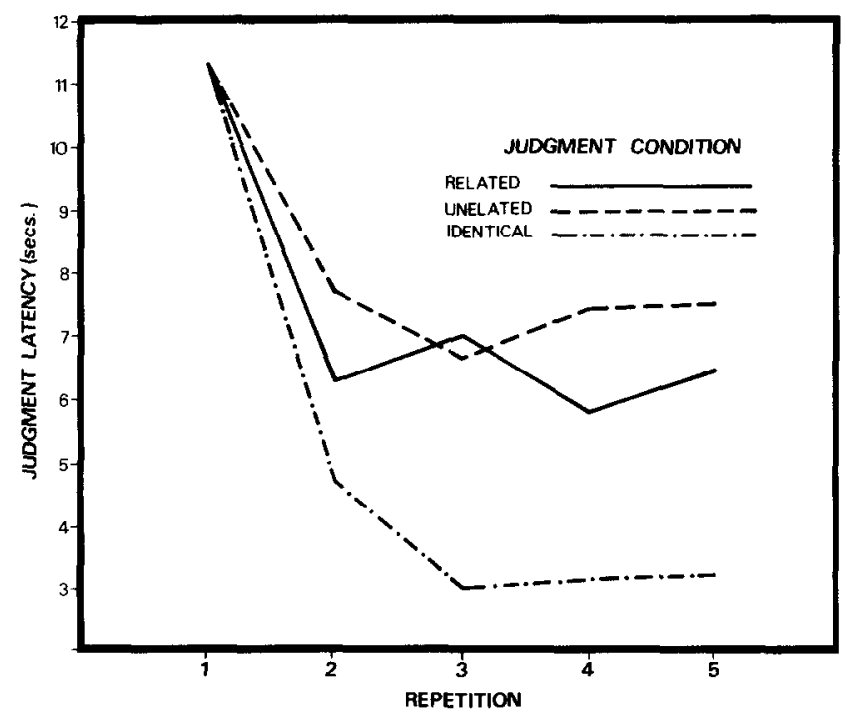

FIG. 5. Judgment latency as a function of judgment repetition and judgment relatedness (Experiment 3). 
in the response. The results were analyzed with and without the confidence component. Both analyses led to the same conclusions. To facilitate comparison to the earlier experiments we report the analyses based on the proportion of correct responses while ignoring the confidence component of that response.

For each subject we computed the proportion of correct responses in each combination of judgment type and number of judgments. Means are presented in Fig. 6. There was a significant number of judgments effect, $F(2,46)=8.26, p<.01$, namely, recognition performance following a single judgment $(0.67)$ was inferior to that following three judgments $(0.77)$ and five judgments (0.81). As in Experiment 1, there was a significant judgment-type effect, $F(2,46)=3.49, p<.05$, with recognition following identical judgments $(0.73)$ being significantly inferior to that following unrelated judgments $(0.81)$ and related judgments $(0.84, t>2.75)$. However, even though the pattern of recognition results for related and unrelated judgments was in the hypothesized direction, the null hypothesis of no difference cannot be rejected $(t=1.03)$. The interaction failed to reach significance, $F(2,46)=1.76, p=.18$.

\section{GENERAL DISCUSSION}

This paper explored the conditions under which individuals use the abstract code or the gist of past judgment instead of stimulus information to arrive at their present judgement. In an impression formation task it was hypothesized that the new impression will tend to be based on an

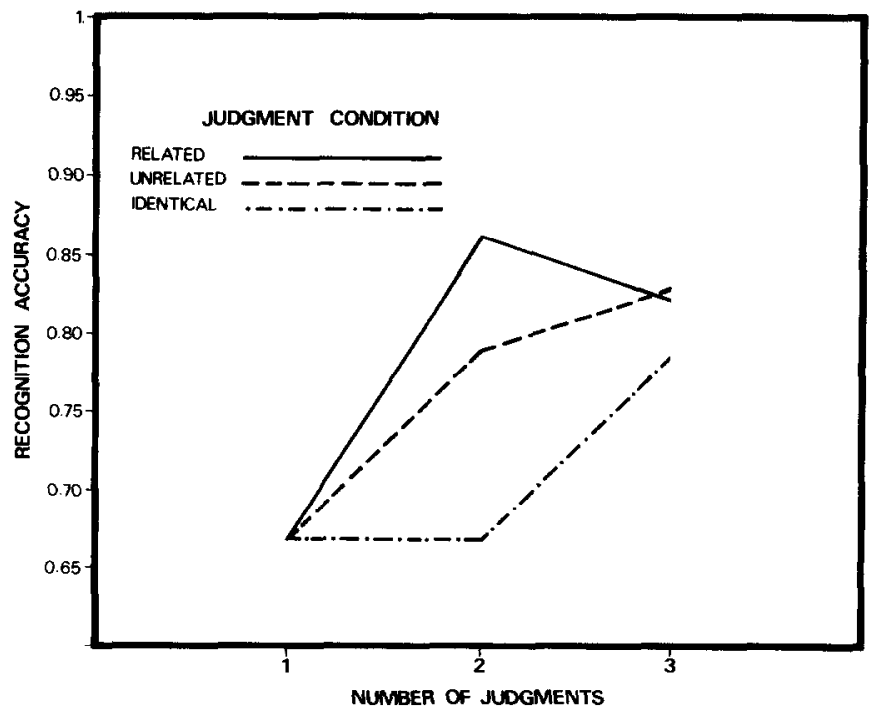

Fig. 6. Recognition accuracy as a function of the number of judgments and their relatedness (Experiment 3). 
old one if the new can be inferred from the old and if the old impression is readily available in memory. Use of the abstract code (rather than the trait information) was indicated in two different ways: First, we assumed that it takes longer to compute a judgment from the stimulus information than to infer it from a previous judgment. Second, it was argued that the use of the stimulus information should be manifested in changes in its representation in memory. Specifically, it was suggested that if the stimulus information is utilized during a judgment, its memory strength (as indicated by a recognition test) will be stronger than when it is not utilized.

Experiments 1 and 3 indicate that the similarity between the present and past judgments affect the extent to which the abstract code is used instead of or in addition to the stimulus information. Experiment 2 pointed out, however, that the effect of similarities between judgments can be moderated considerably by reducing the availability of the abstract code. That is to say, when an interpolated activity, here, other judgments, occurred between the old and new judgments, individuals tended to use the stimulus information regardless of the degree of similarity between the judgments.

Our theorectical account of the findings rests on the assumption that the three types of judgment differed only in the similarity of their underlying dimensions. However, it can be argued that since the traits used to anchor the related scales were different from those used to anchor the unrelated or identical scales (see Footnote 1), the differences attributed to judgment type were mediated by the idiosyncratic features of the traits themselves. In order to explore this possibility we examined the results from the single judgments in the three experiments and tested to see whether there are differences due to the type of judgment. Obviously, since these data were based on a single judgement, any such difference indicates systematic differences between the trait dimensions underlying the three types of judgments. In fact, there were no significant differences due to judgment type for judgment latency, $F(2,114)=2.51, p=.09$, or for accuracy $(F<1)$. The respective means for the related, unrelated, and identical judgment conditions were $9.35,9.92$, and 10.07 for latency and were $0.67,0.68$, and 0.68 for accuracy.

It can be argued that with repeated judgments the representation of the stimulus information become increasingly primed, and hence, the stimulus information can be categorized or interpreted more quickly (Higgins \& King, 1981; Schvaneveldt, Meyer, \& Becker, 1976). Since identical judgments require activation of the same encoding structure each time whereas unrelated judgments require activation of different memory structures, the facilitation produced by priming during identical judgments will be greater than that produced during unrelated judgments. As a result, it should be easier to process the stimulus information when 
the judgments are identical than when they are unrelated. This model, therefore, makes the same prediction in respect to judgment latency as our own.

The two models differ, however, in respect to predictions about the consequences of repeated judgments for the representation of the stimulus information in memory. The difference between the two models has to do with whether and when the stimulus information is activated and elaborated upon. If the stimulus information is activated during each of the judgments, and the decrease in judgment latencies is produced by the increase in priming, than recognition performance should be best following identical judgments. This was clearly not the case. It seems that even though the stimulus information was readily available, individuals used their past impressions and not the stimulus information while making identical judgments.

It has been suggested that once a judgment is formed it is stored separately from the stimulus information (e.g., N. Anderson \& Farkas, 1973; N. Anderson \& Hubert, 1963; Posner \& Snyder, 1975; Schul, 1983). Alternatively, Wyer et al. (1984) argued recently that the gist or impression as well as the stimulus information underlying it are stored within a single representatifon (see also Loken, 1984). Such a single-representation model implies that activation of a central element, such as the impression, ought to increase the activation level of every element in the representation, including, of course, the stimulus information. This seems to be inconsistent with our findings. At least in the case of identical judgments, subjects in Experiments 1 and 3 were able to bring to mind the old judgments and ignore the knowledge that originally gave rise to it. Thus, our results indicate that the abstract code, the impression, may be stored separately and accessed independently of the stimulus information.

Separating the abstract code of the past judgment from the representation of the underlying stimulus information may prove useful in arriving at a general understanding of attitudinal phenomena (cf. Loken, 1984). In particular it suggests that attitudes can be formed in two distinct ways, either by integrating some stimulus information and abstracting the attitude from it or by computing the attitude on the basis of a past attitude, without taking into account the information underlying the latter. Most of the social psychological research has focused on the relationship between the underlying information and the resultant attitude (e.g., N. Anderson, 1981). Still, research does demonstrate the existence of "attitude-based" attitudes. Hartley (1946), for example, showed that people were quite capable of forming attitudes about a nonexistent ethnic group. Clearly, such attitudes cannot be based on knowledge about the groups, but must follow from some inferential process by which judgments about the nonexistent groups are derived from those toward existing ones. The Halo 
effect found in impression formation (e.g., Kaplan, 1975) is also consistent with this phenomenon.

Finally, a caveat is in order. If one had asked subjects in Experiment 2 to try to recall their previous judgments, it is likely that in many cases they would have succeeded (cf. Lingle \& Ostrom, 1979). Still, the results suggests that past judgments were only minimally utilized. Thus, information that was available for one task (i.e., recall) was not available for another (i.e., judgment). Availability, then, is not simply a function of whether or not the stimulus information is in memory. It is also determined by the goals of performance. This may partly explain the low correlations typically found between the recall of stimulus information and its impact on the judgment (e.g., N. Anderson \& Hubert, 1963; Dreben, Fiske, \& Hastie, 1979; Greenwald, 1968; Riskey, 1979; Wyer et al., 1984).

\section{REFERENCES}

Alba, J. W., \& Hasher, L. (1983). Is memory schematic. Psychological Bulletin, 93, 203231.

Anderson, J. R. (1976). Language, memory, and thought. Hillsdale, NJ: Erlbaum.

Anderson, N. H. (1968). Likableness rating of 555 personality trait words. Journal of Personality and Social Psychology, 9, 272-279.

Anderson, N. H. (1981). Integration theory applied to cognitive response and attitudes. In R. E. Petty et al. (Eds.), Cognitive responses in persuasion. Hillsdalc, NJ: Erlbaum.

Anderson, N.H., \& Farkas, A. J. (1973) New light on order effects in attitude change. Journal of Personality and Social Psychology, 28, 88-93.

Anderson, N. H., \& Hubert, S. (1963). Effects of concomitant verbal recall on order effects in personality impression formation. Journal of Verbal Learning and Verbal Behavior, 2, 379-391.

Bransford, J. D., Barclay, J. R., \& Franks, J. J. (1972). Sentence memory: A constructive vs. interpretive approach. Cognitive Psychology, 3, 193-209.

Burnstein, E., \& Schul, Y. (1982). The informational basis of social judgments: The operations in forming an impression of another person. Journal of Experimental Social Psychology, 18, 217-234.

Burnstein, E., \& Schul, Y. (1983). The informational basis of social judgments: Memory for integrated and nonintegrated trait descriptions. Journal of Experimental Social Psychology, 19, 49-57.

Carlston, D. E. (1980). The recall and use of traits and events in social inference processes. Journal of Experimental Social Psychology, 16, 303-328.

Craik, F. I. M., \& Tulving, E. (1975), Depth of processing and the retention of words in episodic memory. Journal of Experimental Psychology, 104, 268-294.

Dreben, E. K., Fiske, S. T., \& Hastie, R. (1979). The independence of evaluative and item information. Impression and recall order effects in behavior based impression formation. Journal of Personality and Social Psychology, 37, 1758-1768.

Ebbesen, E. B. (1980). Cognitive processes in understanding ongoing behavior. In R. Hastie et al. (Eds.), Person memory: The cognitive basis of social perception. Hillsdale. NJ: Erlbaum.

Greenwald, A. G. (1968). Cognitive learning, cognitive response to persuasion and attitude change. In A. Greenwald, et al. (Eds.), Psychological foundations of attitudes. New York: Academic Press, pp. 147-170.

Hartley, E. (1946). Problems in prejudice. New York: Kings Crown Press. 
Hartwick, J. (1979). Memory for trait information: A signal detection analysis. Journal of Experimental Social Psychology, 15, 533-552.

Hastie, R., \& Kumar, P. A. (1979). Person memory: Personality traits as organizing principles in memory for behaviors. Journal of Personality and Social Psychology, 37, 25-38.

Higgins, T. E., \& King, G. (1981). Accessibility of social constructs: Information consequences of individual and contextual variability. In N. Cantor and J. F. Kihlstrom (Eds.), Personality, cognition and social interaction. Hillsdale, NJ: Erlbaum, pp. 69-117.

Higgins, E. T., \& Rhodes, W. S. (1976). Impression formation and role fulfillment: A "holistic reference" approach. Journal of Experimental Social Psychology, 12, 422435.

Hintzman, D. L. (1974). Theoretical implications of the spacing effect. In R. L. Solso (Ed.), Theories in cognitive psychology: The Loyola symposium. Potomac, MD: Erlbaum.

Hintzman, D. L. (1976). Repetition and memory. In G. H. Bower (Ed.), The psychology of learning and motivation (Vol. 10). New York: Academic Press.

Jacoby, L. T. (1978). On interpreting the effects of repetition: Solving a problem versus remembering a solution. Journal of Verbal Learning and Verbal Behavior, 17, 639_ 667.

Johnston, W. A., \& Uhl, C. (1976). The contribution of encoding effort and variability to spacing effect on free recall. Journal of Experimental Psychology: Human Learning and Memory, 2, 153-160.

Nathan, B. R., \& Lord, K. G. (1983). Cognitive categorization and dimensional schemata: A process approach to the study of Halo effect in performance rating. Journal of Applied Psychology, 68, 102-114.

Kaplan, M. F. (1975). Evaluative judgments are based on evaluative information: Evidence against meaning change in evaluative context effects. Memory \& Cognition, 3, 375380.

Lingle, J. H., Dukerich, J. M., \& Ostrom, T. M. (1983). Accessing information in memorybased impression judgments: Incongruity versus negativity in retrieval selectivity. Journal of Personality and Social Psychology, 44, 262-272.

Lingle, J. H., Geva, N., Ostrom, T. M., Leippe, M., \& Baumgardner, M. H. (1979). Thematic effects of person judgments on impression organization. Journal of Personality and Social Psychology, 37, 674-687.

Lingle, J. H., \& Ostrom, T. M. (1979). Retrieval selectivity in memory-based impression judgments. Journal of Personality and Social Pscyhology, 37, 180-194.

Loken, B. (1984). Attitude processing strategies. Journal of Experimental Social Psychology, 20, 272-296.

Mandler, G. (1980). Recognizing: The judgment of previous occurrence. Psychological Review, 87, 252-271.

Posner, M. I., \& Snyder, C. R. (1975). Attention and cognitive control. In R. L. Solso (Ed.), Information processing and cognition: The Loyola symposium. Hillsdale, NJ: Erlbaum.

Reder, L. M. (1979). The role of elaborations in memory for prose. Cognitive Psychology, 11, 221-234.

Riskcy, D. R. (1979). Verbal memory processes in impression formation. Journal of Experimental Psychology: Human Learning and Memory, 5, 271-281.

Rosenberg, S. (1977). New approaches to the analysis of personal constructs in person perception. Nebraska Symposium on Motivation, 24, 179-241.

Schneider, D. J., \& Blankmaker, B. L. (1983). Prototype salience and implicit personality theories. Journal of Personality and Social Psychology, 44, 712-722.

Schul, Y. (1983). Integration and abstraction in impression formation. Journal of Personality and Social Psychology, 44, 45-54. 
Schul, Y., \& Burnstein, E. (1983). The informational basis of social judgments: Memory for informative and uninformative arguments. Journal of Experimental Social Psychology, $19,422-433$.

Schvaneveldt, R., Meyer, D. E., \& Becker, C. A. (1976). Lexical ambiguity, semantic context and visual word recognition. Journal of Experimental Psychology: Human Perception and Performance, 2, 243-256.

Shaughnessy, J. J. (1976). Persistence of spacing effect in free recall under varying incidental learning conditions. Memory \& Cognition, 4, 369-377.

Sherman, S. J., Zehner, K. S., Johnson, J., \& Hirt, E. (1983). Social explanation: The role of timing, set, and recall on subjective likelihood estimates. Journal of Personality and Social Psychology, 44, 1127-1143.

Smith, E. E., Adams, N., \& Schorr, D. (1978). Fact retrieval and the paradox of interference. Cognitive Psychology, 10, 438-464.

Smith, E. P. (1984). Model of social inference processes. Psychological Review, 91, 392413.

Taylor, S. E., \& Crocker, J. (1981). Schematic bases of social information processing. In T. E. Higgins et al. (Eds.), Social cognition: The Ontario symposium (Vol. 1). Hillsdale, NJ: Erlbaum.

Tsujimoto, R. N. (1978). Memory bias toward normative and novel trait prototypes. Journal of Personality and Social Psychology, 36, 1391-1401.

Wyer, R. S., \& Srull, T. K. (1981). Category accessibility: Some theoretical and empirical issues concerning the processing of social stimulus information. In T. E. Higgins et al. (Eds.), Social cognition: The Ontario symposium (Vol. 1). Hillsdale, NJ: Erlbaum.

Wyer, R. S., Srull, T. K., \& Gordon, S. E. (1984). The effects of predicting a person's behavior on subsequent trait judgments. Journal of Experimental Social Psychology, 20, 29-46. 